\title{
IMPLEMENTASI METODE MINKOWSKY DISTANCE UNTUK DETEKSI KELAHIRAN BAYI PREMATUR BERBASIS CASE BASED REASONING
}

\author{
Rabiah Adawiyah \\ Program studi Sistem Informasi, Fakultas Teknologi Informasi \\ Universitas Sembilanbelas November Kolaka \\ Email: bia.fti@usn.ac.id
}

(Naskah masuk: 18 Maret 2020, diterima untuk diterbitkan: 27 Maret 2020)

\begin{abstract}
Abstrak
Kematian bayi di Indonesia sekitar 56\% terjadi pada periode sangat dini yaitu di masa neonatal atau bayi baru lahir. Sebagian besar kematian neonatal terjadi pada usia 0-6 hari (78,5\%) dan prematuritas merupakan penyebab utama kematian neonatal. Bayi prematur atau dalam istilah medis yaitu persalinan preterm merupakan bayi lahir hidup yang dilahirkan sebelum usia kehamilan 37 minggu (antara 20-37 minggu) atau dengan berat janin kurang dari 2500 gram. Untuk mengetahui status kelahiran bayi, ibu hamil seharusnya melakukan konsultasi kepada bidan, namun dalam memberikan informasi kepada pasien ibu hamil, khususnya bidan baru yang belum memiliki banyak pengalaman dalam menangani kasus kelahiran bayi prematur masih mengalami kesulitan untuk mengambil keputusan, sehingga kehamilan prematur baru akan diketahui setelah pasien ibu hamil didiagnosis akan melahirkan dengan usia kehamilan belum mencapai kehamilan 37 minggu. Penalaran Berbasis Kasus atau Case Based Reasoning (CBR) adalah salah satu metode pendekatan berbasis pengetahuan untuk mempelajari dan memecahkan masalah berdasarkan pengalaman yang sebelumnya pernah terjadi dengan cara menentukan fungsi kemiripan (similarity) kasus lama dengan kasus baru. Penelitian ini menggunakan CBR untuk mendeteksi kelahiran bayi prematur menggunakan metode Minkowsky Distance. Berdasarkan Pengujian akurasi sistem yang telah dilakukan maka diperoleh sistem CBR tersebut mampu mendeteksi kelahiran bayi prematur dengan tingkat akurasi sistem sebesar $90 \%$.
\end{abstract}

Kata kunci: Minkowsky Distance, Kelahiran Bayi Prematur, Case Based Reasoning

\section{IMPLEMENTATION OF THE MINKOWSKY DISTANCE METHOD FOR DETECTION OF PRETERM BIRTHS BASED ON CASE BASED REASONING}

\begin{abstract}
Infant mortality in Indonesia around 56\% occurs in a very early period, namely in the neonatal or newborn period.Most neonatal deaths occur at the age of 0-6 days (78.5\%) and prematurity is the leading cause of neonatal death. Pregnancy is called a full month if it lasts between 37-41 weeks from the first day of the menstrual cycle to the 28 day cycle. Premature babies or in medical term that is preterm labor is a live born baby before 37 weeks' gestation (between 20 -37 weeks') or with a fetus weighing less than 2500 grams. To find out the status of the birth of a baby, pregnant women should consult a midwife, but in providing information to pregnant women patients, especially new midwives who do not have much experience in handling cases of preterm births still have difficulty making decisions, so that new premature pregnancies will be known after the patient is diagnosed with a pregnant woman giving birth with gestational age has not reached 37 weeks of pregnancy. Case Based Reasoning is a knowledge- based approach to learning and solving problem based on previous experience by determining the similarity of old cases to new cases. This study uses CBR to detect preterm births using the minkowsky distance method. Based on system accuracy testing that has been carried out, it is obtained that the CBR system as able to detect preterm births with a system accuracy rate of $90 \%$.
\end{abstract}

Keywords: Minkowsky Distance, preterm birth, Case Based Reasoning

\section{PENDAHULUAN}

Kematian bayi di Indonesia sekitar $56 \%$ terjadi pada periode sangat dini yaitu di masa neonatal atau bayi baru lahir. Sebagian besar kematian neonatal terjadi pada usia $0-6$ hari $(78,5 \%)$ dan prematuritas merupakan penyebab utama kematian neonatal [1]. Kehamilan merupakan salah satu hal yang dapat mempengaruhi kelangsungan hidup janin dan kualitas hidupnya. Umumnya kehamilan disebut cukup bulan apabila berlangsung antara 37-41 minggu dihitung dari hari pertama siklus haid terakhir 
pada siklus 28 hari. Sedangkan persalinan yang terjadi sebelum usia kandungan mencapai 37 minggu disebut dengan persalinan prematur. Kejadian kelahiran prematur berbeda pada setiap negara. Pada negara maju, misalnya Eropa, angkanya berkisar antara 5-11\%, di USA, pada tahun 2000 sekitar satu dari sembilan bayi dilahirkan prematur $(11,9 \%)$, dan di Australia kejadiannya sekitar 7\%. Sementara itu, misalnya di India sekitar 30\%, Afrika Selatan sekitar $15 \%$, Sudan $31 \%$. Angka kejadian kelahiran prematur di Indonesia pada tahun 1983 sebesar 18,5\% dan menurun pada tahun 1995 menjadi 14,2\% [2]. Untuk mengetahui status kelahiran bayi, ibu hamil seharusnya melakukan konsultasi kepada bidan, namun dalam memberikan informasi kepada pasien ibu hamil, khsususnya bidan baru yang belum memiliki banyak pengalaman dalam menangani kasus kelahiran bayi prematur masih mengalami kesulitan untuk mengambil keputusan, sehingga kehamilan prematur baru akan diketahui setelah pasien ibu hamil didiagnosis akan melahirkan dengan usia kehamilan belum mencapai kehamilan 37 minggu. Teknologi Penalaran Berbasis Kasus (Case Based Reasoning) CBR yang dapat digunakan untuk mendiagnosis penyakit pada kehamilan. Dalam penelitian ini konsep-konsep dalam CBR dijelaskan sesuai dengan studi kasusnya, meliputi teknik penyimpanan data kasus, pencarian kemiripan atau kesamaan kasus, dan menghasilkan solusi sesuai dengan yang diinginkan dengan pembagian kriteria kemiripan antar lain High, Medium, Low akan memudahkan dalam memilih kasus yang memiliki kemiripan paling tinggi dengan kasus baru [3]. Pada penelitian ini peneliti memilih metode minkowsky berdasarkan penelitian terdahulu yaitu CBR untuk Diagnosis penyakit Infeksi saluran pernapasan akut menggunakan metode Minkowsky Distance yang memberikan hasil akurasi sistem dengan tingkat pengujian menggunakan $\mathrm{K}-$ Fold cross validation $\mathrm{K}=7$ dengan nilai treshold $>=60 \%$ menghasilkan tingkat akurasi sistem sebesar 99,29\% [4]. Berdasarkan beberapa penelitian terdahulu maka pada penelitian digunakan metode Minkowsky Distance berbasis CBR agar dapat membantu tenaga medis dalam mendeteksi kelahiran bayi prematur.

\section{METODE PENELITIAN}

\subsection{Case Based Reasoning (CBR)}

CBR adalah sebuah model penalaran yang menggabungkan pemecahan masalah, pemahaman dan pembelajaran, dan mengintegrasikannya ke dalam proses penyimpanan. Terdapat 4 tahapan dalam CBR yaitu Retrieval, Reuse, Revise dan Retain. Pada tahapan Retrieval dilakukan proses mencari kemiripan kasus antara Target case dan Source case yang disebut dengan proses Similarity kasus [5]. Tahapan CBR dapat dilihat pada Gambar 1.

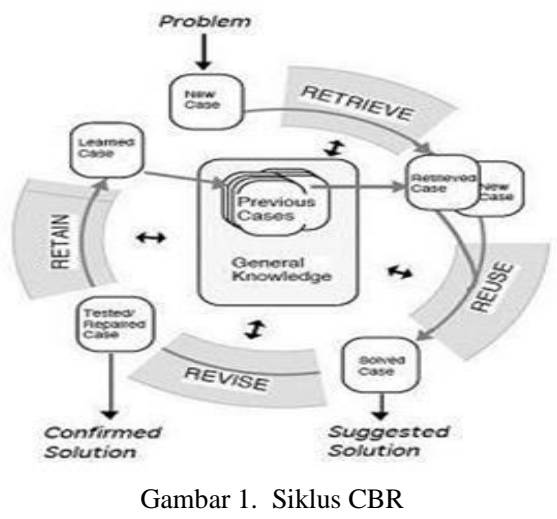

\subsection{Proses Retrieval}

salah satu metode yang digunakan dalam teknik retrieval adalah similarity metric, yaitu dengan menentukan ukuran kedekatan/similaritas antar kasus. Terdapat 2 (dua) macam pengukuran similaritas, yaitu similaritas lokal dan similaritas global. Similaritas lokal adalah pengukuran kedekatan pada level fitur, sedangkan similaritas global adalah pengukuran kedekatan pada level objek (kasus).

a. Similarity Lokal

Similaritas lokal merupakan similarity yang dilakukan untuk menunjukkan kesamaan antar atribut. Dalam penelitian ini dibedakan menjadi 2 (dua) jenis data yaitu data bertipe numerik dan simbolik. Data yang bersifat numerik akan dihitung menggunakan persamaan (1) sedangkan data bersifat simbolik dihitung menggunakan persamaan (2).

$$
f\left(S_{k}, T_{k}\right)=1-\frac{\left|S_{k}-T_{k}\right|}{R}
$$

Dimana, $S_{k}, T_{k}$ adalah nilai Fitur yang akan dicari kemiripan atributnya sedangkan $\mathrm{R}$ adalah range nilai terkecil dan terbesar yang digunakan untuk atribut tersebut [6].

$$
f\left(S_{k}, T_{k}\right)=\left\{\begin{array}{l}
1 \text { jika } S=T \\
0 \text { jika } S \neq T
\end{array}\right.
$$

Dimana, nilai 1 digunakan apabila nilai $\mathrm{S}$ dan $\mathrm{T}$ dianggap mirip dan nilai 0 akan digunakan apabila nilai s dan tidak mirip [7]

\section{b. Similarity Global}

Similarity Global yang digunakan dalam penelitian ini yaitu metode Minkowsky Distance. Kemudian metode tersebut digunakan setelah nilai dari masing- masing atribut pada similarity lokal telah diketahui. Metode ini merupakan pengembangan dari metode City Block Distance dengan nilai $\mathrm{r}=1$, Euclidien Distance dengan nilai $\mathrm{r}=2$ dan apabila nilai $\mathrm{r}=$ infinity (tak terhingga) dikenal nama Chebyshev Distance [8]. Minkowsky Distance digunakan dengan nilai $r=3$. Adapun rumus yang digunakan pada similarity Global sesuai dengan persamaan 3 . [9] 


$$
\begin{gathered}
\operatorname{Sim}(S, T)= \\
{\left[\frac{\left.\sum_{k=1}^{n}\left(W_{k, P} P(S)\right)^{r} *\left|f\left(S_{k}, T_{K}\right)^{r}\right|\right)}{\left.\sum_{k=1}^{n}\left(W_{k} P(S)\right)^{r}\right)}\right]} \\
1 / r
\end{gathered}
$$

Dimana, $\mathrm{n}$ adalah banyak atribut, $\mathrm{r}$ adalah nilai factor Minkowsky digunakan nilai $(\mathrm{r}=3), W_{k}, P(S)$ adalah nilai bobot atribut $\mathrm{ke}-\mathrm{k}$ pada source case dan $f\left(S_{k}, T_{k}\right)$ adalah nilai dari similarity lokal yang $\mathrm{sdh}$ diketahui.

\subsection{Pengukuran tingkat keyakinan}

Pengukuran tingkat keyakinan dalam CBR adalah identik antara target case dan source case. Tingkat keyakinan pada target case merupakan bagian dari sebuah kelas dalam source case. Dapat dihitung menggunakan persamaan 4. [10]

$$
P_{K}\left(S_{K}, T_{K}\right)=P_{K}\left(S_{K}\right) * \frac{J\left(S_{K, n} T_{K,}\right)}{J\left(T_{K}\right)}
$$

Dimana, $P_{K}\left(S_{K}, T_{K}\right)$ adalah tingkat keyakinan target case $(\mathrm{T})$ terhadap source case $(\mathrm{S}), P_{K}\left(S_{K}\right)$ adalah tingkat keyakinan pakar dalam usatu kasus ke - k terhadap Source case, $J\left(S_{K}, T_{K},\right)$ adalah banyaknya atribut kasus $\mathrm{T}$ yang sama dengan kasus $\mathrm{S}$ dan $J\left(S_{K}, T_{K},\right)$ adalah banyaknya atribut pada kasus $\mathrm{T}$.

Rumus Similarity Global kemudian dimodifikasi dengan menambahkan pengukuran tingkat keyakinan dengan menggunakan persamaan 5 .

$\operatorname{Sim}(S, T)=\left[\frac{\left.\sum_{k=1}^{n}\left(W_{k}, P(S)\right)^{r} *\left|f\left(S_{k}, T_{K}\right)^{r}\right|\right)}{\left.\sum_{k=1}^{n}\left(W_{k} P(S)\right)^{r}\right)}\right] \quad 1 / r *$

$P_{K}\left(S_{K}\right) * \frac{J\left(S_{K,,}, T_{K,}\right)}{J\left(T_{K}\right)}$

\subsection{Pengujian Sistem}

Pengujian sistem dilakukan pengukuran Akurasi yaitu tingkat kedekatan pengukuran kuantitas terhadap nilai yang sebenarnya. Pengukuran akurasi dilakukan dengan membandingkan jumlah diagnosis benar antara hasil sistem dengan banyaknya data riil sebagai data uji yang digunakan, Perbandingan tersebut menggunakan persamaan 6 . [11].

$$
\text { akurasi }=\frac{\sum \text { diagnosis benar }}{\text { banyaknya data } u j i} * 100 \%
$$

\section{HASIL DAN PEMBAHASAN}

\subsection{Diagram Konteks}

Diagram Konteks Sebuah teknis grafis yang menggambarkan aliran informasi dan transformasi yang diaplikasikan pada saat data bergerak dari input menjadi output. Rancangan dari sistem yang diusulkan menggunakan notasi-notasi yang menggambarkan arus masuk dan keluarnya data pada suatu sistem yang penggunaannya sangat membantu memahami sistem secara logika, terstruktur dan jelas. Penelitian ini menggambarkan diagram konteks dengan entitas terdiri atas 3 yaitu admin, Pakar dan paramedis. Diagram konteks CBR untuk mendeteksi kelahiran bayi prematur dapat dilihat pada gambar 2 .

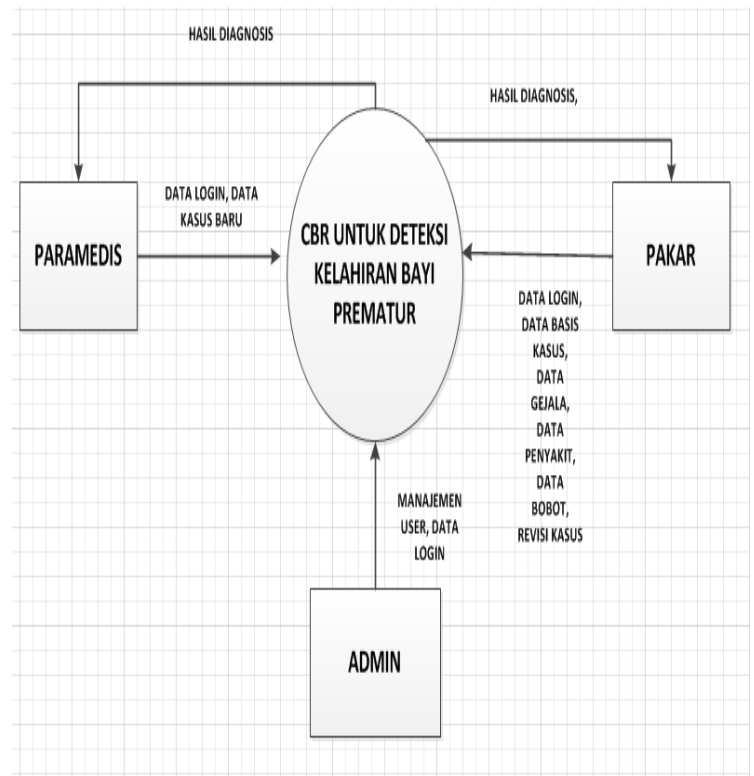

Gambar 2. Diagram Konteks CBR untuk Deteksi kelahiran bayi prematur

\subsection{Proses Diagnosis}

Sistem CBR ini proses diagnosis yang terjadi yaitu memperhatikan gejala yang terdiri dari 18 gejala dan 3 faktor resiko lainnya yaitu usia, tafsiran berat janin dan grafik kehamilan. Berdasarkan data yang digunakan gejala bernilai data simbolik apabila gejala pada target case ditemukan juga pada source case maka akan bernilai 1 dan apabila tidak ditemukan maka bernilai 0 sedangkan usia, tafsiran berat janin dan grafik kehamilan menggunakan data numerik yang nilainya akan dihitung berdasarkan range nilai terendah dan tertinggi. Data gejala yang bernilai simbolik dapat menggunakan persamaan 1 dan data faktor resiko lainnya yang datanya bernilai numerik dapat menggunakan persamaan 2. Setelah nilai masing atribut (similarity lokal) diperoleh, maka selanjutnya melakukan Perhitungan similarity Global pada target case dengan menggunakan persamaan 5 . Tabel 1 merupakan Contoh Representasi Target case sedangkan tabel 2 merupakan contoh Representasi Source case menggunakan 2 data rekam medis pasien yang telah mempunyai hasil diagnosis. Kemudian akan di lakukan proses similarity antara target case dan source case menggunakan metode Minkowsky Distance. 
Tabel 1. Representasi Target case

\begin{tabular}{rlc}
\hline \multicolumn{1}{c}{ Atribut } & nilai \\
\hline \multicolumn{2}{c}{ No_kasus } & RM_84 \\
Faktor Resiko : & \\
1. $\quad$ Tafsiran Berat Janin & $1595 \mathrm{mg}$ \\
2. & Grafik Kehamilan & 1 \\
3. & Umur & $38 \mathrm{thn}$ \\
Gejala : & \\
1. & Serviks Inkompeten & Ya \\
2. & Leukositosis & Ya \\
3. & Ketuban Pecah Dini & Ya \\
4. & Solutio Plasenta & Ya \\
\hline Hasil Diagnosis : & $\ldots \ldots \ldots \ldots \ldots$ \\
\hline
\end{tabular}

Tabel 2. Representasi Source case

\begin{tabular}{lll}
\hline \multicolumn{1}{c}{ Atribut } & \multicolumn{1}{c}{ Nilai } & Bobot \\
\hline No_kasus : & RM_40 & \\
Faktor Resiko : & & 4 \\
1. Tafsiran Berat Janin & 1800 & 3 \\
2. Grafik Kehamilan & 3 & 4 \\
3. Umur & 30 & \\
Gejala : & & 5 \\
1. Ketuban Pecah Din & Ya & 5 \\
2. Solutio Plasenta & Ya & 5 \\
3. Serviks Inkompeten & Ya & 2 \\
4. Omentum & Ya & Kelahiran Premature \\
Hasil Diagnosis : & $100 \%$ & \\
Keyakinan Pakar & & \\
& RM_65 & \\
No_kasus : & & 4 \\
Faktor Resiko : & 3800 & 3 \\
1. Tafsiran Berat Janin & 3 & 4 \\
2. Grafik Kehamilan & 20 & \\
3. Umur & & 3 \\
Gejala : & Ya & 5 \\
4. Omentum & Ya & \\
5. Leukositosis & Ya & \\
6. Oligahidrom ion & Kelahiran Normal \\
Hasil Diagnosis : & $100 \%$ & \\
Keyakinan Pakar & & \\
& &
\end{tabular}

Pada Tabel 1 Representasi target case belum diketahui hasil diagnosisnya, untuk itu akan dilakukan proses similarity lokal terhadap masing masing atribut. Tabel 2 merupakan representasi source case yang sudah mempunyai hasil diagnosis yang akan dijadikan rujukan untuk hasil diagnosis pada target case. Berikut akan dilakukan similarity lokal untuk setiap atribut pada target case dan source case.

a. Perhitungan Similarity Lokal

Menggunakan persamaan 1 untuk data yang numerik. Menghitung kemiripan untuk Target case (T) terhadap Source case (S) dengan RM_40.

1. Atribut Tafsiran Berat Badan

$$
f(s, t)=1-\left|\frac{1595-1800}{3800-1200}\right|=1-\frac{205}{2600}=0.92
$$

2. Grafik Kehamilan

3. Umur

$$
f(s, t)=1-\left|\frac{1-3}{5-0}\right|=1-\frac{2}{5}=0.6
$$

$$
f(s, t)=1-\left|\frac{38-30}{45-1}\right|=1-\frac{8}{44}=0.81
$$

Ket misalnya atribut umur diperoleh angka 45 dan 1 , dari data basis kasus rekam medis pasien yaitu 45 adalah data nilai maksimal dan 1 adalah data nilai minimal.
Menggunakan persamaan 2 untuk data yang simbolik.Menghitung kemiripan untuk Target case (T) terhadap Source case (S) dengan RM_40.

4. Kedekatan Gejala

- Untuk gejala di Target case yaitu ketuban pecah, solutio Plasenta dan Serviks Inkompeten bernilai 1 karena gejala tersebut ada ( muncul) pada Source case.

- Untuk gejala di target case Leukositosis bernilai 0 karena gejala tersebut tidak ada ( tidakmuncul ) pada Source case.

b. Perhitungan Similarity Global

$\operatorname{Sim}(S, T)$

$=\left[\frac{(0.81 * 4)^{3}+(0.6 * 3)^{3}+(0.92 * 4)^{3}+(1 * 5)^{3}+(0 * 3)^{3}+(1 * 5)^{3}+(1 * 5)^{3}}{4^{3}+3^{3}+4^{3}+5^{3}+3^{3}+5^{3}+5^{3}}\right]$

$$
\operatorname{Sim}(S, T)=\left[\frac{34.01+5.83+49.83+125+0+125+125}{64+27+64+125+27+125+125}\right]^{1 / 3}
$$

$$
\operatorname{Sim}(S, T)=\left[\frac{464.68}{557}\right] \quad{ }^{1 / 3} * \frac{6}{7} * 100 \%=0.80=80 \%
$$

.Menghitung kemiripan untuk Target case (T) terhadap Source case (S) dengan RM_80.

1. Atribut Tafsiran Berat Badan

$$
f(s, t)=1-\left|\frac{1595-3800}{3800-1200}\right|=1-\frac{2205}{2600}=0.15
$$

2. Grafik Kehamilan

3. Umur

$$
f(s, t)=1-\left|\frac{1-3}{5-0}\right|=1-\frac{2}{5}=0.6
$$

$$
f(s, t)=1-\left|\frac{38-20}{45-1}\right|=1-\frac{18}{44}=0.59
$$

Menggunakan persamaan 2 untuk data yang simbolik.Menghitung kemiripan untuk Target case (T) terhadap Source case (S) dengan RM_65.

4. Kedekatan Gejala

- Untuk gejala di Target case yaitu ketuban pecah, solutio Plasenta dan Serviks Inkompeten bernilai 0 karena gejala tersebut tidak ada ( tidak muncul ) pada Source case.

- Untuk gejala di target case Leukositosis bernilai 1 karena gejala tersebut ada (muncul) pada Source case.

c. Perhitungan Similarity Global

$\operatorname{Sim}(S, T)$

$=\left[\frac{(0.15 * 4)^{3}+(0.6 * 3)^{3}+(0.59 * 3)^{3}+(0 * 5)^{3}+(1 * 3)^{3}+(0 * 3)^{3}+(0 * 3)^{3}}{4^{3}+3^{3}+4^{3}+5^{3}+3^{3}+5^{3}+5^{3}}\right]$

$$
\begin{gathered}
\operatorname{Sim}(S, T)=\left[\frac{0,, 21+5.83+13.14+0+27+0+0}{64+27+64+125+27+125+125}\right] \quad 1 / 3 \\
\operatorname{Sim}(S, T)=\left[\frac{46.19}{557}\right] \quad 1 / 3 * \frac{4}{7} * 100 \%=0.25=25 \%
\end{gathered}
$$

Berdasarkan perhitungan contoh kasus menggunakan Metode Minkowsky Distance yang telah dilakukan, maka diperoleh hasil perhitungan untuk source case RM_40 dengan hasil diagnosis kelahiran Bayi 
Prematur diperoleh nilai 0.80 atau $80 \%$ dan untuk source case RM_65 dengan hasil diagnosis kelahiran Bayi Normal diperoleh nilai 0.25 atau $25 \%$. Sehingga hasil diagnosis untuk target case (kasus baru) adalah nilai terbesar yaitu kelahiran Bayi Prematur dengan tingkat kemiripan kasus sebesar $80 \%$.

\subsection{Hasil Pengujian}

Pengujian akurasi sistem dilakukan untuk mengukur kemampuan sistem dalam mendeteksi kelahiran bayi prematur dengan menggunakan pesamaan 6. Proses ini dilakukan dengan menggunakan 20 data uji. Dari 20 data uji kasus baru terdapat 13 data dengan diagnosis prematur dan 7 data dengan diagnosis normal. Masing-masing data kemudian dimasukan ke dalam sistem untuk dilakukan proses pengujian. Berdasarkan hasil pengujian tersebut masing-masing terdapat 2 data yang hasil diagnosisnya tidak sesuai (false) dengan nilai dibawah treshold yaitu <=60 yang selengkapnya dapat dilihat pada Tabel 3.

Tabel 3. Hasil pengujian Sistem

\begin{tabular}{lllll}
\hline No_RM & Hasil & Hasil & Nilai & Ket \\
& Riil & Sistem & Similarity & \\
\hline RM_80 & Prematur & Prematur & $92.87 \%$ & Ya \\
RM_80 & Prematur & Normal & $42.82 \%$ & tidak \\
RM_80 & Prematur & Prematur & $87.55 \%$ & Ya \\
RM_80 & Prematur & Prematur & $80.18 \%$ & Ya \\
RM_80 & Prematur & Prematur & $72.97 \%$ & Ya \\
RM_80 & Prematur & Prematur & $88.80 \%$ & Ya \\
RM_80 & Prematur & Prematur & $95.37 \%$ & Ya \\
RM_80 & Prematur & Prematur & $73.81 \%$ & Ya \\
RM_80 & Prematur & Prematur & $84.12 \%$ & Ya \\
RM_80 & Prematur & Prematur & $91.86 \%$ & Ya \\
RM_80 & Prematur & Prematur & $92.00 \%$ & Ya \\
RM_80 & Prematur & Prematur & $80.00 \%$ & Ya \\
RM_80 & Prematur & Prematur & $98.77 \%$ & Ya \\
RM_80 & Prematur & Prematur & $96.23 \%$ & Ya \\
RM_95 & Normal & Normal & $89.73 \%$ & Ya \\
RM_95 & Normal & Normal & $80.89 \%$ & Ya \\
RM_95 & Normal & Prematur & $58.97 \%$ & tidak \\
RM_95 & Normal & Normal & $92.18 \%$ & ya \\
RM_95 & Normal & Normal & $86.50 \%$ & ya \\
RM_95 & Normal & Normal & $91.75 \%$ & ya \\
\hline
\end{tabular}

Berdasarkan tabel 3 hasil pengujian dapat diperoleh dari total 20 data uji, nilai data uji dengan hasil diagnosis benar berjumlah 18 kasus dan data uji dengan hasil diagnosis False berjumlah 2 kasus. Maka dapat dihitung nilai akurasinya sebagai berikut

$$
\begin{gathered}
\text { Akurasi Sistem }=\frac{12+6}{20}=\frac{18}{20}=0.9 * 100 \% \\
\text { Akurasi Sistem }=90 \%
\end{gathered}
$$

Sistem Implementasi metode Minkowsky Distance untuk deteksi kelahiran bayi prematur berbasis CBR berdasarkan hasil pengujian akurasi sistem mampu menghasilkan tingkat akurasi sebesar $90 \%$.

\section{KESIMPULAN}

Setelah melakukan rancang bangun, implementasi dan pengujian terhadap sistem Case Base Reasoning (CBR) untuk mendeteksi bayi lahir prematur menggunakan metode Minkowsky distance maka diperoleh kesimpulan bahwa :

1. Penelitian ini mampu mendeteksi bayi lahir prematur dan Normal menggunakan sistem CBR dengan cara melakukan similarity pada Source case dan Target case berdasarkan fitur usia, grafik kehamilan, berat bayi, dan gejala yang dialami oleh ibu hamil.

2. Pengujian sistem yang dilakukan dari 20 data uji kasus baru diperoleh tingkat akurasi sistem sebesar $90 \%$.

\section{DAFTAR PUSTAKA}

[1] E. Eliza., D, Nuryani., dan R, Rosmiyati, 2017. "Determinan persalinan premature di RSUD Dr.Abdul Moeloek", Jurnal Kesehatan, Volume VIII, Nomor 2, pp 305-309.

[2] J. E. Lawn., M, G, Gravett, Nunes TM, Rubens CE, Stanton C, dan GAAPS Review Group. Global Report on Preterm Birth and Stillbirth (1 Of 7): Definitions, Deskriptions of The Burden and Apportunities to Improve Data. BMC Pregnancy and Childbirth. 10 (Suppl 1):S1.2010.

[3] S. Muzid., 2008. 'Teknologi Penalaran Berbasis Kasus (Case Based Reasoning) Untuk Diagnosa Penyakit Kehamilan". Seminar Nasional Aplikasi Teknologi Informasi (SNATI) (Vol. 1, No. 1).

[4] M. Salmin., dan S, Hartati., 2018. "Case Based Reasoning untuk diagnosis Penyakit pernapasan Akut", JIKO (Jurnal Informatika dan Komputer), Vol.2 no.1, pp.21-26

[5] S. K. Pal., S, C, K, Shiu., 2004. Foundations of Soft Case-Based Reasoning. Wiley-Interscience Publication, New Jersey.

[6] Nurdiansyah. Y dan Hartati. S, 2014, Case Based Reasoning untuk pendukung diagnosis gangguan pada anak autis, Thesis, Prodi S2/S3 Ilmu Komputer, UGM , Yogyakarta.

[7] R. Adawiyah., 2018, "Case Based Reasoning untuk Diagnosis Hama dan Penyakit Tanaman Nilam" Jurnal INTENSIF (Teknologi dan Penerapan Sistem Informasi), Vol.2 No.1, Februari 2018.

[8] J. M. Mergio dan M. Casanovas., 2008, "The Induced Minkowski Ordered Weighted Averaging Distance Operator, ESTYLF08, Cuencas Mineras (Mieres-Langreo)", Congreso Espanol sobre Tecnologiasy Logica Fuzzy, pp 35-41.

[9] H. Nunez., M. S. Marre., U. Cortes., J. Comas., M. Martinez., I. R. Roda dan M. Poch., 2004, “A comparative study on the use of similarity measures in case based reasoning to improve the 
classification of environmental system situations, Original Research Article", EnvironmentalModelling \& Software, Volume 19, Issue 9,

[10] U. A. Mancasari., 2012. "Sistem Pakar Menggunakan Penalaran Berbasis Kasus untuk Mendiagnosis Penyakit Syaraf pada Anak", Skripsi. S1 Ilmu Komputer UGM. Yogyakarta.

[11] I. H. Witten dan E. Frank., 2005, "Data Mining : Practical Machine Learning Tools and Techniques, 2", Morgan Kaufmann Publisher, SanFransisco 